\title{
Tracing and inhibiting growth of Staphylococcus aureus in barbecue cheese production after product recall
}

\author{
S. Johler, K. Zurfluh, and R. Stephan ${ }^{1}$ \\ Institute for Food Safety and Hygiene, Vetsuisse Faculty University of Zurich, 8057 Zurich, Switzerland
}

\begin{abstract}
Staphylococcal food poisoning is one of the most prevalent causes of foodborne intoxication worldwide. It is caused by ingestion of enterotoxins formed by Staphylococcus aureus during growth in the food matrix. Following a recall of barbecue cheese due to the detection of staphylococcal enterotoxins in Switzerland in July 2015, we analyzed the production process of the respective dairy. Although most cheese-making processes involve acidification to inhibit the growth of pathogenic bacteria, barbecue cheese has to maintain a $\mathrm{pH}>6.0$ to prevent undesired melting of the cheese. In addition, the dairy decided to retain the traditional manual production process of the barbecue cheese. In this study, therefore, we aimed to (1) trace Staph. aureus along the barbecue cheese production process, and (2) develop a sustainable strategy to inhibit growth of Staph. aureus and decrease the risk of staphylococcal food poisoning without changing the traditional production process. To this end, we traced Staph. aureus in a step-wise blinded process analysis on 4 different production days using spa (Staphylococcus protein A gene) typing, DNA microarray profiling, and pulsedfield gel electrophoresis analysis. We subsequently selected a new starter culture and used a model cheese production including a challenge test assay to assess its antagonistic effect on Staph. aureus growth, as well as its sensory and technological implications. We detected Staph. aureus in 30\% (37/124) of the collected samples taken from the barbecue cheese production at the dairy. This included detection of Staph. aureus in the final product on all 4 production days, either after enrichment or using quantitative detection. We traced 2 enterotoxigenic Staph. aureus strains (t073/CC45 and t282/CC45) colonizing the nasal cavity and the forearms of the cheesemakers to the final product. In the challenge test assay, we were able to show that the new starter culture inhibited growth of Staph. aureus while
\end{abstract}

Received November 27, 2015.

Accepted January 21, 2016.

${ }^{1}$ Corresponding author: roger.stephan@uzh.ch meeting the sensory and technological requirements of barbecue cheese production.

Key words: Staphylococcus aureus, contamination routes, process analysis, barbecue cheese, starter culture

\section{INTRODUCTION}

In July 2015, the Swiss Federal Food Safety and Veterinary Office (Bern) issued a warning concerning the consumption of barbecue cheese, in which Staphylococcus aureus and staphylococcal enterotoxins ( $\mathbf{S E}$ ) had been detected. The dairy producing the barbecue cheese issued a recall, followed by a comprehensive external process analysis to trace Staph. aureus in the cheese-making process.

Staphylococcus aureus can cause staphylococcal food poisoning (SFP), the most prevalent foodborne intoxication worldwide. Ingestion of major or newly described SE (Hennekinne et al., 2010; Johler et al., 2015) formed during growth of the organism in food leads to symptoms of acute gastroenteritis and violent emesis (Hu and Nakane, 2014). Although symptoms usually subside within $24 \mathrm{~h}$, SFP can, in rare cases, be fatal for children and the elderly. The Centers for Disease Control and Prevention (Atlanta, GA) estimates 240,000 cases per year in the United States, resulting in 1,000 hospitalizations and 6 deaths (Scallan et al., 2011).

As SE are heat-stable and will not be inactivated during the cooking process, preventive measures focus on inhibiting growth of Staph. aureus in the food matrix (Le Loir et al., 2003). To this end, starter cultures are used in the production of a wide range of foods including cheese. A suitable starter culture will outcompete the organism, thus effectively preventing Staph. aureus growth and SE formation. However, starter cultures need to meet several criteria to be suitable for the production of barbecue cheese. Although the antagonistic effect of many starter cultures is due to acidification of the food matrix, the $\mathrm{pH}$ of barbecue cheese cannot be lowered to values $<6.0$, as this would result in melting of the cheese when it is exposed to high temperatures during preparation by the customer. In addition, suitable starter cultures must have no negative sensory implications. 
In this study, we aimed to (1) trace Staph. aureus in the barbecue cheese production process, and (2) develop a sustainable strategy to inhibit growth of Staph. aureus and decrease the risk of SFP without changing the traditional production process.

\section{MATERIALS AND METHODS}

\section{Sampling Along the Production Process and Isolation of Coagulase-Positive Staphylococci}

To identify potential sources for contamination of the barbecue cheese at the dairy, 4 production cycles (see Figure 1) of the barbecue cheese were screened for coagulase-positive staphylococci in a blinded setup. To avoid bias, the dairy and the cheesemakers were only informed of the results upon completion of the study. Samples were taken from cheesemakers and at each step of the cheese-making process on August $24\left(\mathbf{T}_{1}\right)$, August $27\left(\mathbf{T}_{\mathbf{2}}\right)$, September $1\left(\mathbf{T}_{\mathbf{3}}\right)$, and September 3 $\left(\mathbf{T}_{4}\right), 2015$ (see Table 1). Before the start of cheese production, swabs from the anterior nares and forearms of the cheesemakers were taken, as well as a swab from the inner and outer side of the end of the milk hose after pasteurization. All swabs were moistened using $0.85 \% \mathrm{NaCl}$. During cheese production, 10-mL samples of milk, whey, and starter cultures, and 30-g samples of curd and cheese were taken. Samples were screened for coagulase-positive staphylococci (CPS) using enrichment in Mueller-Hinton broth with $6.5 \% \mathrm{NaCl}$ and plating on rabbit plasma fibrinogen (RPF) agar (Oxoid, Pratteln, Switzerland) and quantitatively, following the EN ISO 6888-2 protocol (ISO, 1999). Species identification of Staph. aureus was achieved through subsequent spa typing and the detection of species-specific markers by Staphytype DNA microarray profiling (Alere, Jena, Germany).

\section{Cell Lysis and DNA Extraction}

For cell lysis and DNA extraction, reagents of the Staphytype genotyping kit 2.0 and the DNeasy Blood and Tissue Kit (Qiagen, Hilden, Germany) were used according to the manufacturers' instructions. The concentration of nucleic acids was measured using a Nanodrop ND-1000 UV/Vis spectrophotometer (NanoDrop Technologies, Wilmington, DE).

\section{spa Typing}

The polymorphic $\mathrm{X}$ region of spa was amplified as previously described (Wattinger et al., 2012). Each PCR product was subsequently purified using the GenElute PCR Clean-Up Kit (Sigma-Aldrich, Buchs, Swit- zerland) and sequencing was outsourced (Microsynth, Balgach, Switzerland). Subsequently, spa types were determined using the spa server (http://spa.ridom.de/; Harmsen et al., 2003).

\section{DNA Microarray-Based Genotyping}

The Staphytype genotyping kit 2.0 was used to detect the presence or absence of over 300 virulence and resistance genes and their allelic variants in Staph. aureus strains that were traced from the cheesemakers to the final product. Detection included genes encoding the major SE (sea, seb, sec, sed, see), as well as genes coding for newly described SE and enterotoxin-like superantigens (seg, seh, sei, sej, sek, sel, selm, seln, selo, seq, ser, selu). Microarray profiles also allowed for assignment of the strains to agr types, as well as clonal complexes (CC; Monecke et al., 2008).

\section{Pulsed-Field Gel Electrophoresis Analysis}

Preparation of chromosomal DNA and pulsed-field gel electrophoresis (PFGE) analysis of SmaI-digested fragments was performed as previously described (Bannerman et al., 1995). Electrophoresis was carried out in a Bio-Rad CHEF-DR III electrophoresis cell (Bio-Rad, Hercules, CA). Salmonella enterica serovar Braenderup strain H9812 digested with $50 \mathrm{U}$ of $\mathrm{Xba \textrm {I }}(12$ $\mathrm{h}, 37^{\circ} \mathrm{C}$ ) was used as a molecular size standard. Gels were analyzed with Gel Compar II software (Applied Maths, Sint-Martens-Latem, Belgium) using the dice coefficient and were represented by unweighted pair grouping by mathematical averaging (UPGMA) with an optimization of $0.5 \%$ and position tolerance of $1 \%$.

\section{Model Cheese Production Including Challenge Test Assay Using New Starter Culture}

A new starter culture, consisting of CNS, was chosen (START Crudo 500, Christl Gewürze GmbH, Moosdorf, Austria). Species identification of CNS was performed by matrix-assisted laser desorption/ionization-timeof-flight mass spectrometry (MALDI-TOF MS). To evaluate the suitability of the new starter culture for the barbecue cheese production, the cheesemakers produced 4 batches of model cheese (batches $\mathrm{A}$ to $\mathrm{D}$ ) in a laboratory setting.

To assess growth of the starter culture during the cheese-making process, we determined CNS counts in 2 barbecue cheese production batches (batches A and B) at 3 time points. The first sample was taken from the curd directly after coagulation, the second sample was obtained from the cheese after pressing (same day), and the third sample was taken in the morning of the 


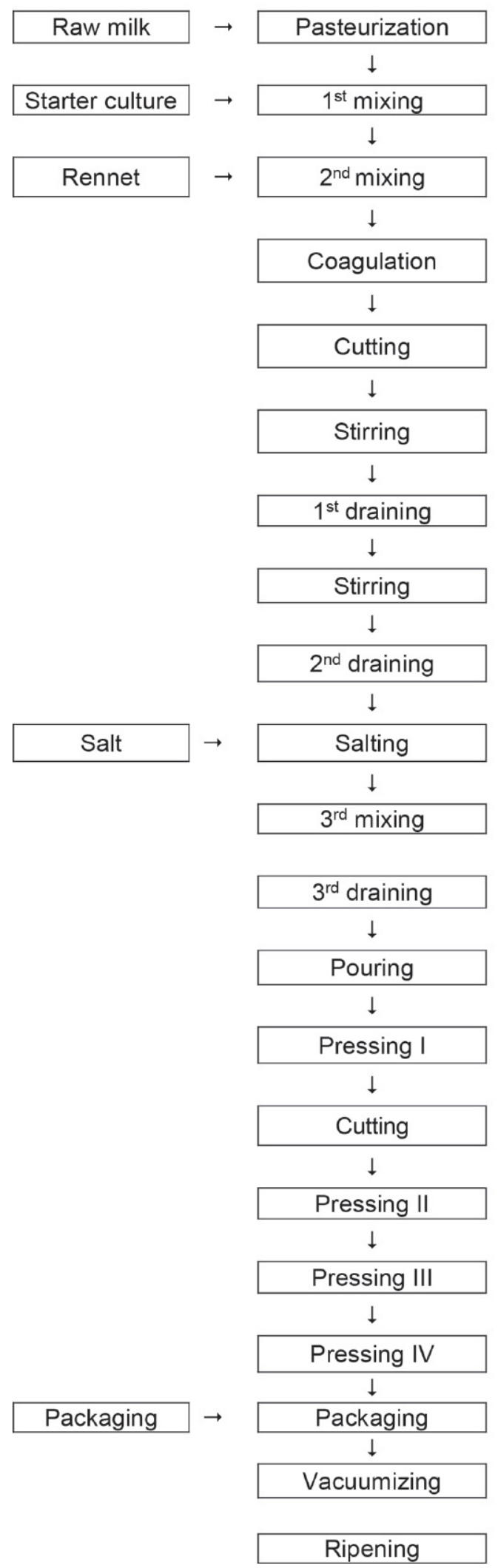

\begin{tabular}{|c|c|c|}
\hline${ }^{\circ} \mathrm{C}$ & Time & $\mathrm{pH}$ \\
\hline 77 & $10 \mathrm{sec}$ & 6.80 \\
\hline 32.5 & & 6.80 \\
\hline 32.5 & & \\
\hline 32.5 & $20 \mathrm{~min}$ & \\
\hline 32.5 & $4 \mathrm{~min}$ & \\
\hline 32 & $10 \mathrm{~min}$ & \\
\hline 32 & $2 \min$ & \\
\hline 48 & $5 \mathrm{~min}$ & \\
\hline 48 & & \\
\hline 48 & $1 \mathrm{~min}$ & 6.10 \\
\hline 48 & $5 \mathrm{~min}$ & \\
\hline 48 & & \\
\hline 47 & $6 \mathrm{~min}$ & \\
\hline 47 & $30 \mathrm{~min}$ & \\
\hline 45 & $4 \mathrm{~min}$ & \\
\hline 42 & $1.5 \mathrm{~h}$ & 6.17 \\
\hline 42 & $4 \mathrm{~h}$ & \\
\hline 42 & $12-14 \mathrm{~h}$ & \\
\hline 42 & & \\
\hline 40 & & \\
\hline 5 & $0-60$ days & \\
\hline
\end{tabular}

Figure 1. Flowchart providing an overview of the barbecue cheese production process until the ripening stage. The average batch size equaled $500 \mathrm{~kg}$ of milk, resulting in $55 \mathrm{~kg}$ of cheese. 
following day. At this time, we also measured the $\mathrm{pH}$ of the cheese.

The inhibitory effect of the new starter culture on Staph. aureus growth was assessed in a challenge assay using 2 batches of barbecue cheese (batches C and D) produced with milk contaminated with Staph. aureus. To this end, a Staph. aureus strain isolated during the step-wise analysis of the barbecue cheese production process (strain 1, isolated at processing step P30, t282) was grown in brain-heart infusion (BHI) broth (Oxoid, Pratteln, Switzerland) at $37^{\circ} \mathrm{C}(225 \mathrm{rpm}$ shaking) overnight to $2.5 \times 10^{9} \mathrm{cfu} / \mathrm{mL}$. From the overnight broth, as well as from its 10 -fold dilution in $0.85 \% \mathrm{NaCl}, 1.0$ $\mathrm{mL}$ was added to $3 \mathrm{~L}$ of milk, resulting in contamination levels of $10^{6} \mathrm{cfu} / \mathrm{mL}$ milk in batch $\mathrm{C}$ and $10^{5} \mathrm{cfu} /$
$\mathrm{mL}$ milk in batch $\mathrm{D}$. The cheeses were sampled after 24 $\mathrm{h}$ and CPS counts were determined following the EN ISO 6888-2 protocol (ISO, 1999).

\section{RESULTS AND DISCUSSION}

We detected Staph. aureus in 30\% (37/124) of the samples collected along the production process of the 4 barbecue cheese production cycles at the dairy (see Table 1). This included detection of Staph. aureus in the final product on all 4 production days, either after enrichment $\left(\mathrm{T}_{1}\right)$ or by quantitative detection methods $\left(\mathrm{T}_{2}\right.$ to $\left.\mathrm{T}_{4}\right)$. The highest CPS count detected in a sample equaled $6.3 \times 10^{5} \mathrm{cfu} / \mathrm{g}$ in the final product, with cell density levels of $10^{5}$ to $10^{6} \mathrm{cfu} / \mathrm{mL}$ generally

Table 1. Tracing Staphylococcus aureus in a step-wise blinded process analysis on 4 different days $\left(\mathrm{T}_{1} \text { to } \mathrm{T}_{4}\right)^{1}$

\begin{tabular}{|c|c|c|c|c|c|c|}
\hline Sample ID & Source & Sampling details & \multicolumn{4}{|c|}{ Result $^{2}$} \\
\hline \multicolumn{7}{|c|}{ Before processing (swabs) } \\
\hline BP2 & Cheesemaker 2 & Nose & t073 (A) & t073 (A) & t073 (A) & t073 (A) \\
\hline BP3 & Cheesemaker 1 & Forearms & t 282 & $\mathrm{t} 362_{\mathrm{e}}$ & - & - \\
\hline $\mathrm{BP} 4$ & Cheesemaker 2 & Forearms & - & t073 (A) & - & t5264 \\
\hline $\mathrm{P} 1$ & Raw milk & & t529 & t3992 & - & - \\
\hline P2 & Milk after pasteurization & Production start & - & - & - & - \\
\hline P3 & Milk after pasteurization & Mid-production & - & - & - & - \\
\hline $\mathrm{P} 4$ & Starter culture & & - & - & - & - \\
\hline P5 & Curd before cutting & Sample 1 & - & - & - & - \\
\hline $\mathrm{P} 6$ & Curd before cutting & Sample 2 & - & - & - & - \\
\hline P7 & Curd before cutting & Sample 3 & - & - & $\mathrm{t} 073_{\mathrm{e}}(\mathrm{A})$ & - \\
\hline $\mathrm{P} 13$ & Curd after 2nd stirring & Sample 2 & - & - & - & $\mathrm{t} 073_{\mathrm{e}}(\mathrm{A})$ \\
\hline P14 & Curd after 2nd stirring & Sample 3 & - & - & - & - \\
\hline $\mathrm{P} 15$ & Whey & 2nd draining & - & - & - & - \\
\hline P16 & Curd after mixing & Sample 1 & - & - & - & - \\
\hline P17 & Curd after mixing & Sample 2 & - & - & - & - \\
\hline P18 & Curd after mixing & Sample 3 & - & - & - & - \\
\hline P19 & Whey & 3rd draining & - & - & - & $\mathrm{t} 282_{\mathrm{e}}(\mathrm{B})$ \\
\hline $\mathrm{P} 20$ & Cheese after pressing I & Sample 1 & - & - & - & - \\
\hline P21 & Cheese after pressing I & Sample 2 & - & - & - & $\mathrm{t} 282_{\mathrm{e}}$ \\
\hline $\mathrm{P} 22$ & Cheese after pressing I & Sample 3 & - & - & - & $\mathrm{t} 282_{\mathrm{e}}$ \\
\hline P23 & Cheese after pressing II & Sample 1 & - & - & - & t5264 \\
\hline P24 & Cheese after pressing II & Sample 2 & - & - & - & $\mathrm{t} 282_{\mathrm{e}}$ \\
\hline P25 & Cheese after pressing II & Sample 3 & - & - & - & t073 \\
\hline P26 & Cheese after pressing III & Sample 1 & - & - & - & $\mathrm{t} 282_{\mathrm{q}}$ \\
\hline
\end{tabular}

${ }^{1}$ The table indicates at which production steps Staph. aureus isolates were detected and provides an overview of the respective spa types (t073, t282, t5264, t529, t3992) and pulsed-field gel electrophoresis (PFGE) patterns (A, B) determined for selected isolates. Three strains could be traced from the cheesemakers to the final product: t072 (A), t282 (B), and t5264.

${ }^{2}$ Letters (A, B) in parentheses indicate assignment of isolates to PFGE patterns. Subscript q $\left(_{q}\right)$ indicates that quantitative detection was possible for coagulase-postive staphylococci counts $>10^{2} \mathrm{cfu} / \mathrm{g}$; subscript e $(\mathrm{e})$ indicates that lower levels were detectable only after enrichment. 
Table 2. Molecular characteristics of the 3 Staphylococcus aureus strains traced from the cheesemakers to the final product

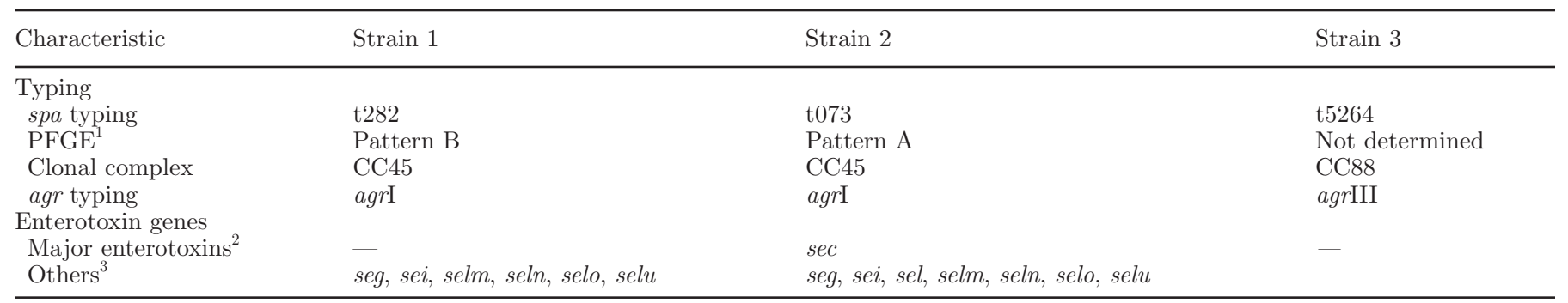

${ }^{1}$ Pulsed-field gel electrophoresis.

${ }^{2}$ Screening included all major enterotoxin genes (sea, seb, sec, sed, and see).

${ }^{3}$ Screening included $s e g$, seh, sei, sej, sek, sel, selm, seln, selo, seq, ser, and selu.

being regarded as sufficient for enterotoxin production. The step-wise analysis showed that, in most cases, lowlevel contamination occurred early in the production process, with Staph. aureus being detected only after enrichment.

To determine the source of the contamination, we traced the isolates along the production process using spa typing, DNA microarray analysis, and PFGE analysis. The 37 isolates represented 6 different spa types: t282 ( $\mathrm{n}=15), \mathrm{t} 073(\mathrm{n}=15), \mathrm{t} 5264(\mathrm{n}=4), \mathrm{t} 362(\mathrm{n}=$ $1)$, t529 ( $\mathrm{n}=1)$, and $\mathrm{t} 3992(\mathrm{n}=1)$. The 3 spa types that were detected only once were found in Staph. aureus strains obtained from raw milk and the forearm of a cheesemaker. As these strains were not present in the final product, we excluded them from further characterization experiments. The DNA microarray analysis and spa typing showed that the remaining 34 isolates could be assigned to 3 distinct Staph. aureus strains. Genotypic characteristics, including typing results, as well as enterotoxin gene profiles of these strains are provided in Table 2. Strains 1 (t282/CC45) and 2 (t073/ CC45) harbored enterotoxin genes and were repeatedly detected in samples from cheesemakers and in the final product. Strain identity of selected isolates was confirmed by PFGE analysis, resulting in only 2 distinct patterns. A third Staph. aureus strain (t5264/CC88) was only found in one production cycle $\left(\mathrm{T}_{4}\right)$ and was shown not to be enterotoxigenic.

Staphylococcus aureus colonizes the skin and mucosa of humans, with nasal carriage rates between 30 and $50 \%$ in the adult population (Diederen et al., 2006; Munckhof et al., 2008; Halablab et al., 2010; Wattinger et al., 2012). The 3 Staph. aureus strains detected in the nasal cavity and on the forearms of the cheesemakers, as well as in the final product, were assigned to t282/CC45, t073/CC45, and t5264/CC88. Staphylococcus aureus isolates of these spa types and clonal complexes have been previously reported in association with asymptomatic colonization and cases of infections in humans (Bloemendaal et al., 2009; Luedicke et al.,
2010; Wattinger et al., 2012; Gómez-Sanz et al., 2013). Nasal carriage status of Staph. aureus is not necessarily permanent but has been shown to change frequently over time (Sakwinska et al., 2009). Although decolonization strategies such as intranasal application of mupirocin and chlorhexidine washing have high success rates immediately after treatment, many carriers will become recolonized during a longer follow-up period (van Rijen et al., 2008; Ammerlaan et al., 2009). Thus, decolonization of cheesemakers does not represent a sustainable approach to increase food safety and promotes the risk of nasal colonization with mupirocin-resistant Staph. aureus (Ammerlaan et al., 2009).

As the dairy decided to retain the traditional manual production of the barbecue cheese, the most promising strategy to increase food safety and reduce the risk of SFP was the inhibition of Staph. aureus growth by use of a new starter culture. The candidate starter culture was identified as Staphylococcus vitulinus by MALDITOF MS. As shown in Table 3, the new starter culture was able to grow under the conditions of the cheesemaking process. It had no negative sensory implications and resulted in a favorable $\mathrm{pH}$ of the product $(\mathrm{pH}$ $=6.29$ ). In the challenge assay, we observed that the starter culture was able to outcompete Staph. aureus (Table 4), with a maximum increase of CPS counts of $1 \log _{10}$. This is particularly remarkable, as physical concentration effects alone can result in an increase of

Table 3. Growth of the starter culture evaluated by CNS counts using a model cheese production ${ }^{1}$

\begin{tabular}{|c|c|c|c|}
\hline \multirow[b]{2}{*}{ Time point } & \multicolumn{2}{|c|}{ Batch A } & \multirow{2}{*}{$\begin{array}{c}\text { Batch B } \\
\frac{(+ \text { Staphylococcus aureus })}{\text { CNS }(\mathrm{cfu} / \mathrm{g})}\end{array}$} \\
\hline & CNS (cfu/g) & $\mathrm{pH}$ & \\
\hline After coagulation & $1.4 \times 10^{6}$ & - & $1.3 \times 10^{6}$ \\
\hline After pressing & $2.2 \times 10^{5}$ & - & $2.5 \times 10^{5}$ \\
\hline Next morning & $2.9 \times 10^{7}$ & 6.29 & $6.0 \times 10^{7}$ \\
\hline
\end{tabular}

${ }^{1}$ Growth in presence of Staph. aureus was determined using an initial milk contamination level of $10^{3} \mathrm{cfu}$ Staph. aureus per milliliter of milk. 
Table 4. Challenge test assay assessing inhibition of Staphylococcus aureus growth by the new starter culture in a model cheese production ${ }^{1}$

\begin{tabular}{lcccc}
\hline & \multicolumn{2}{c}{$\begin{array}{c}\text { Coagulase-positive } \\
\text { staphylococci (CPS) }\end{array}$} & CNS \\
\cline { 2 - 3 } \cline { 5 - 5 } Batch & $\begin{array}{c}\text { Artificial contamination } \\
\text { in milk (cfu/mL) }\end{array}$ & $\begin{array}{c}\text { After } 24 \mathrm{~h} \\
(\mathrm{cfu} / \mathrm{g})\end{array}$ & & $\begin{array}{c}\text { After } 24 \mathrm{~h} \\
(\mathrm{cfu} / \mathrm{g})\end{array}$ \\
\hline $\mathrm{C}$ & $10^{6}$ & $2.0 \times 10^{7}$ & & $2.4 \times 10^{8}$ \\
$\mathrm{D}$ & $10^{5}$ & $6.0 \times 10^{5}$ & & $2.1 \times 10^{8}$ \\
\hline
\end{tabular}

${ }^{1}$ Growth of Staph. aureus and the new starter culture was quantified using CPS and CNS counts, respectively.

$1 \log _{10}$ during the cheese-making process (Peng et al., 2013).

\section{CONCLUSIONS}

We conclude that although the pasteurization process of the raw milk used for barbecue cheese production was successful, the risk of SFP persists due to Staph. aureus contamination by colonized cheesemakers. As decolonization of food handlers cannot ensure long-term freedom from nasal or skin carriage, the most promising strategy to increase food safety in the traditional manual production process is the use of a suitable starter culture. We were able to show that the new Staphylococcus vitulinus starter culture inhibited growth of Staph. aureus while meeting the sensory and technological requirements of barbecue cheese production. The dairy has now successfully implemented the new starter culture in the production process of the barbecue cheese and resumed regular production.

\section{ACKNOWLEDGMENTS}

We thank the cheesemaker and the dairy for their cooperation and we thank Sabrina Corti (Institute for Food Safety and Hygiene, University of Zurich) for technical assistance. We acknowledge funding by the Swiss National Research Program 69 (40690_145211/1).

\section{REFERENCES}

Ammerlaan, H. S. M., J. A. J. W. Kluytmans, H. F. L. Wertheim, J. L. Nouwen, and M. J. M. Bonten. 2009. Eradication of methicillin-resistant Staphylococcus aureus carriage: A systematic review. Clin. Infect. Dis. 48:922-930.

Bannerman, T. L., G. A. Hancock, F. C. Tenover, and J. M. Miller. 1995. Pulsed-field gel electrophoresis as a replacement for bacteriophage typing of Staphylococcus aureus. J. Clin. Microbiol. 33:551-555.

Bloemendaal, A. L. A., A. C. Fluit, W. M. T. Jansen, M. R. Vriens, T. Ferry, L. Argaud, J. M. Amorim, A. C. Resende, A. Pascual, L. López-Cerero, S. Stefani, G. Castiglione, P. Evangelopoulou, S. Tsiplakou, I. H. M. B. Rinkes, and J. Verhoef. 2009. Acquisi- tion and cross-transmission of Staphylococcus aureus in European intensive care units. Infect. Control Hosp. Epidemiol. 30:117-124.

Diederen, B. M. W., M.-L. van Leest, I. van Duijn, P. Willemse, P. H. J. van Keulen, and J. A. J. W. Kluytmans. 2006. Performance of MRSA ID, a new chromogenic medium for detection of methicillinresistant Staphylococcus aureus. J. Clin. Microbiol. 44:586-588.

Gómez-Sanz, E., C. Torres, C. Lozano, and M. Zarazaga. 2013. High diversity of Staphylococcus aureus and Staphylococcus pseudintermedius lineages and toxigenic traits in healthy pet-owning household members. Underestimating normal household contact? Comp. Immunol. Microbiol. Infect. Dis. 36:83-94.

Halablab, M. A., S. M. Hijazi, M. A. Fawzi, and G. F. Araj. 2010. Staphylococcus aureus nasal carriage rate and associated risk factors in individuals in the community. Epidemiol. Infect. 138:702706.

Harmsen, D., H. Claus, W. Witte, J. Rothgänger, H. Claus, D. Turnwald, and U. Vogel. 2003. Typing of methicillin-resistant Staphylococcus aureus in a university hospital setting by using novel software for spa repeat determination and database management. J. Clin. Microbiol. 41:5442-5448.

Hennekinne, J.-A., A. Ostyn, F. Guillier, S. Herbin, A.-L. Prufer, and S. Dragacci. 2010. How should staphylococcal food poisoning outbreaks be characterized? Toxins (Basel) 2:2106-2116.

Hu, D.-L., and A. Nakane. 2014. Mechanisms of staphylococcal enterotoxin-induced emesis. Eur. J. Pharmacol. 722:95-107.

ISO. 1999. EN ISO 6888-2 Microbiology of food and animal feeding stuffs - Horizontal method for the enumeration of coagulase-positive Staphyloccocci (Staphylococcus aureus and other species): Part 2: Technique using rabbit-plasma fibrinogen agar medium. International Organisation for Standardisation, Geneva, Switzerland.

Johler, S., P. Giannini, M. Jermini, J. Hummerjohann, A. Baumgartner, and R. Stephan. 2015. Further evidence for staphylococcal food poisoining outbreaks caused by egc-encoded enterotoxins. Toxins (Basel) 7:997-1004.

Le Loir, Y., F. Baron, and M. Gautier. 2003. Staphylococcus aureus and food poisoning. Genet. Mol. Res. 2:63-76.

Luedicke, C., P. Slickers, R. Ehricht, and S. Monecke. 2010. Molecular fingerprinting of Staphylococcus aureus from bone and joint infections. Eur. J. Clin. Microbiol. Infect. Dis. 29:457-463.

Monecke, S., P. Slickers, and R. Ehricht. 2008. Assignment of Staphylococcus aureus isolates to clonal complexes based on microarray analysis and pattern recognition. FEMS Immunol. Med. Microbiol. $53: 237-251$.

Munckhof, W. J., G. R. Nimmo, J. Carney, J. M. Schooneveldt, F. Huygens, J. Inman-Bamber, E. Tong, A. Morton, and P. Giffard. 2008. Methicillin-susceptible, non-multiresistant methicillin-resistant and multiresistant methicillin-resistant Staphylococcus aureus infections: A clinical, epidemiological and microbiological comparative study. Eur. J. Clin. Microbiol. Infect. Dis. 27:355-364.

Peng, S., W. Hoffmann, W. Bockelmann, J. Hummerjohann, R. Stephan, and P. Hammer. 2013. Fate of Shiga toxin-producing and generic Escherichia coli during production and ripening of semihard raw milk cheese. J. Dairy Sci. 96:815-823.

Sakwinska, O., G. Kuhn, C. Balmelli, P. Francioli, M. Giddey, V. Perreten, A. Riesen, F. Zysset, D. S. Blanc, and P. Moreillon. 2009. Genetic diversity and ecological success of Staphylococcus aureus strains colonizing humans. Appl. Environ. Microbiol. 75:175-183.

Scallan, E., R. M. Hoekstra, F. J. Angulo, R. V. Tauxe, M.-A. Widdowson, S. L. Roy, J. L. Jones, and P. M. Griffin. 2011. Foodborne illness acquired in the United States-Major pathogens. Emerg. Infect. Dis. 17:7-15.

van Rijen, M. M. L., M. Bonten, R. P. Wenzel, and J. A. Kluytmans. 2008. Intranasal mupirocin for reduction of Staphylococcus aureus infections in surgical patients with nasal carriage: A systematic review. J. Antimicrob. Chemother. 61:254-261.

Wattinger, L., R. Stephan, F. Layer, and S. Johler. 2012. Comparison of Staphylococcus aureus isolates associated with food intoxication with isolates from human nasal carriers and human infections. Eur. J. Clin. Microbiol. Infect. Dis. 31:455-464. 